appears to me, however, that the plugs differ from the comedones of later life in being formed from the epithelial lining of the follicle, and not from sebum, in various stages of imperfect elaboration. I do not think that mere uncleanly habits or external irritation from confined sweat or linings of head gear will satisfactorily account for their production, albeit the predominance in boys, and exclusive occurrence in hospital patients, though by no means of the dirtiest class, are to be noted. A parasitic cause suggests itself so forcibly that I have carefully sought for such in a great number of the extracted plugs. As might be expected, micro-organisms are to be found, but I have nothing definite to bring forward on this head. I have never found the Demodex folliculorum. In the distal end of each of three or four comedones from one case I found a mass of big spores, indistinguishable to my eye from trichophyton. Probably the nutritional defect owns none of these causes.

The treatment is very simple. The plugs are easily extracted, and their removal is facilitated and re-formation hindered by the local use of alkaline and stimulating applications, and of these thorough shampooing with soap and water is one of the most efficacious. There is, moreover, a tendency in many cases for the comedones to disappear of their own accord after a few months.

The conclusion arrived at is that in this affection we have to do with an eruption of comedones peculiar in their composition and derivation, and in their site and distribution; in their tendency to grouping and close setting; in their tendency to evolve suddenly, to appear in spring and summer, to come and go, and to disappear in winter; in their occurrence in children, especially of the male sex; and in their tendency to affect simultaneously several children of a family.

\section{ON TRACHEOTOMY TUBES.}

BY PUGIN THORNTON,

FORMERLY SURGEON TO THE HOSPITAL FOR DISEASES OF THE THROAT, GOLDEN SQUARE.

For many years past it has seemed to me to be a regrettable circumstance that there was not a more general consensus of opinion on the form of tracheotomy tube most suitable for use. I will briefly describe and illustrate the various tubes in common request; I will then give a list of surgical instrument makers and dealers in London whom I visited on the 2 nd and 27 th of last month, and the tube or tubes recommended by them to any purchaser; and lastly I will state what, in my opinion, is the best form of tube to use

FIG. 1.

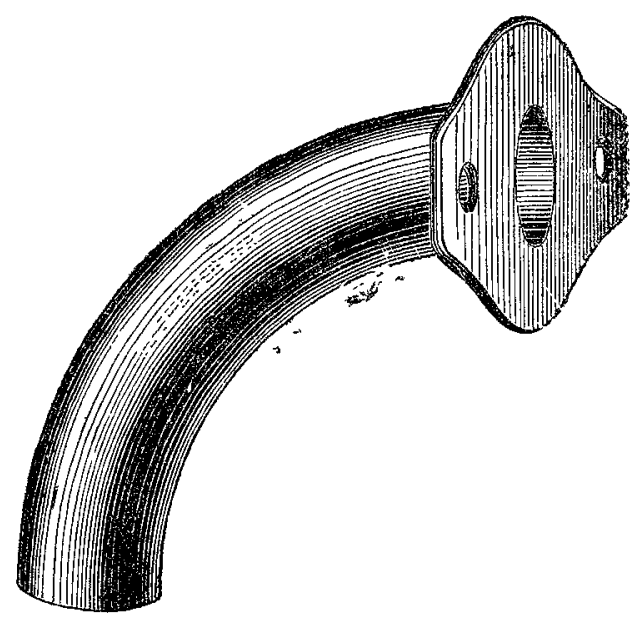

and my reasons for considering it so. By this paper I hope to draw a general attention to the importance of securing a tracheotomy tube which shall be so universally recognised in this country as the most suitable for the surgeon and the patient that no preference for one tube or another shall arise from the cheapness of the article, or from some localised cause, such as the advice of a friend who has little personal acquaintance with the operation of tracheotomy, or the recommendation of an instrument maker. It is often that a surgeon, who has little knowledge of the different forms of tracheotomy tubes requiring one in a hurry, takes the advice of his instrument maker; and it frequently happens that instrument makers, knowing no single recognised form of tube, recommend one which is by no means the best for their customer to use.

Tracheotomy tubes are made on two principles. One is the quarter-circle shape, as Trousseau's or Bryant's tubes, and Fuller's or Matthews' bivalve; in the other the tracheal end of the tube is at right angles to the shank, asin Durham's, or with a modified right angle, as in Hilton's or Parker's.

Trousseau's tube (Fig. 1) is on the principle of all old quarter-circle cannulæ. It should be represented in the woodcut with an inner tube. Inner tubes were invented by Martin in 1737 .

FIG, 2.

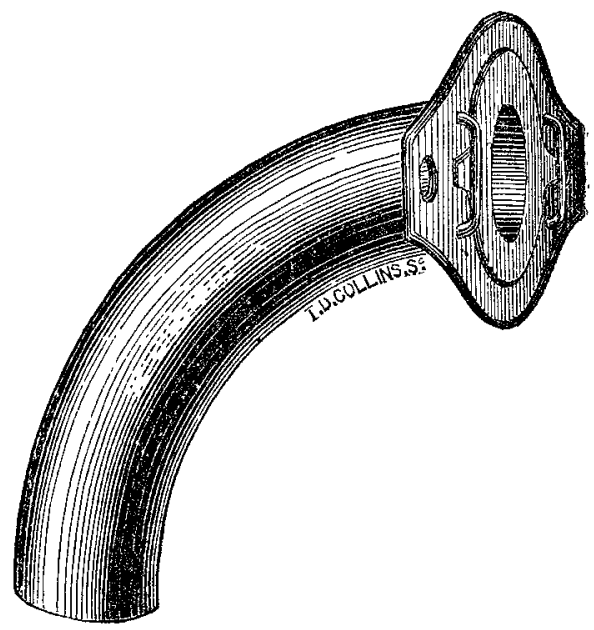

Roger's (Fig. 2) improvement on Trousseau's, in making the tube movable on the neck-plate, is carried out at the present day in all forms of cannulæ, whether of quartercircle or of right-angle shape.

Bryant's tube, by means of a joint in the neck-plate, is

FIG. 3.

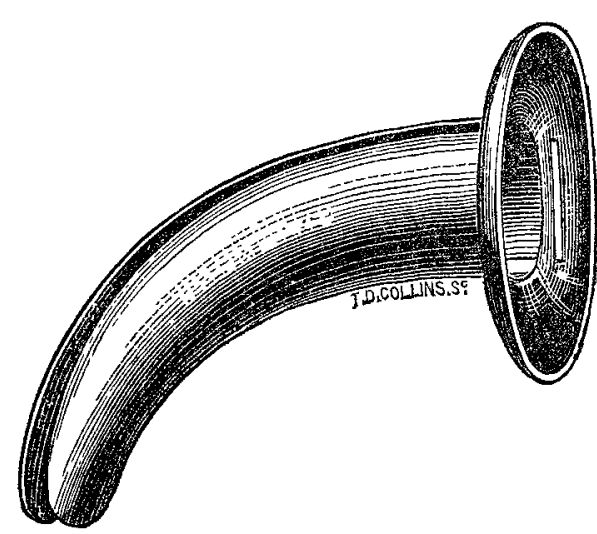

made more movable still, but the joint makes it cumbersome, It can be slightly shortened, if required.

On this quarter-circle principle the bivalve cannule (Figs, 3 and 4) now known as the bivalve or Matthews' tube (with a ring in place of the solid shield-plate), an

\section{Fig. 4.}

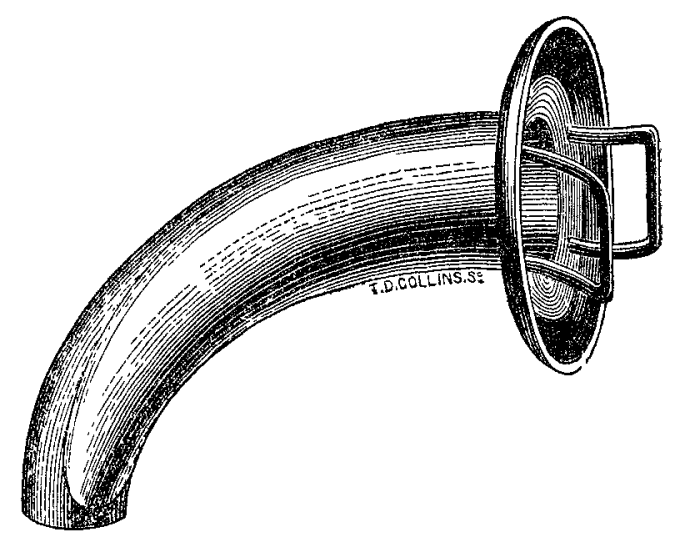

improved form of Fuller'e, like Liston's, is made. Curiously. it appears, it is in constant use at St. Bartholomew's Hospital, notwithstanding the warning given some years ago by one of its surgeons, Mr. Howard Marsh, of its aptitude in 
causing fatal hæmorrhage by reason of the sharpness of the forwards, and the tube altered to the length required edges of its outer cannula. It is maintained by some that this tube is easily passed into the trachea. Forceps have been made (Mr. O. Sankey) to pass through slits in the shield, and so squeezing the bivalves together to facilitate

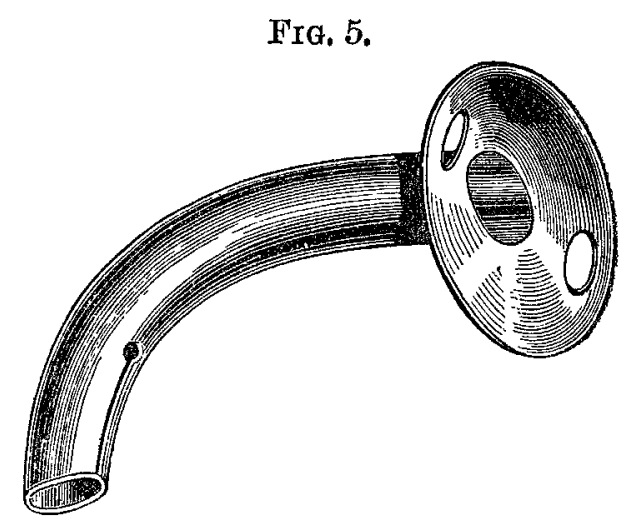

its passage through the tracheal opening. Instrument makers say that this tube, excepting the one on the old form of Roger's pattern, which costs about, the same, is the cheapest kind of tube they sell.

Hilton's (Figs. 5 and 6 ), the first, I believe, made of right-

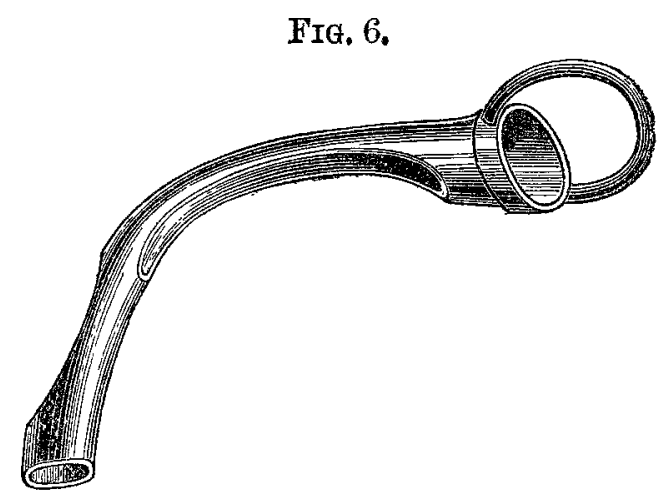

angle shape, was brought forward about twenty-five years ago by the celebrated surgeon of Guy's Hospital.

Mr. R. W. Parker first made his tube very similar to Hilton's. He has now the tracheal portion still more at a

FIG. 7.

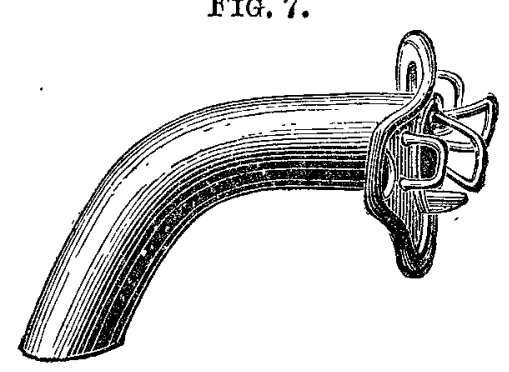

right angle. (Fig. 7.) The upper wall of tho inner cannula of this tube has largely to be cut away (not so much as the lower wall of Hilton's inner tube, Fig. 6 ), or it would not pass the angle in the outer cannula.

\section{FIG. 8.}

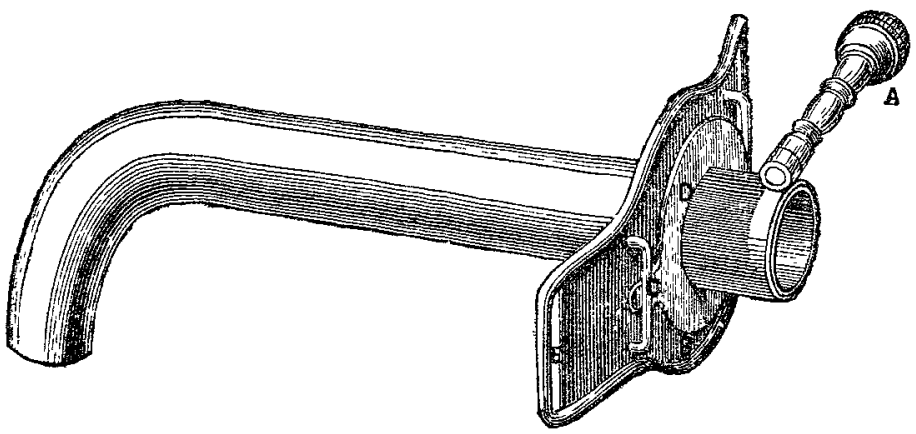

Mr. Durham, another Guy's Hospital surgeon, who invented a most serviceable tube, brought out his instrument (Fig. 8) in 1869. By means of a screw in the necklet of the outer cannula of this tube the shield can be pushed backwards or

(Fig. 9)-undeniably a most useful circumstance at the FIG.9.

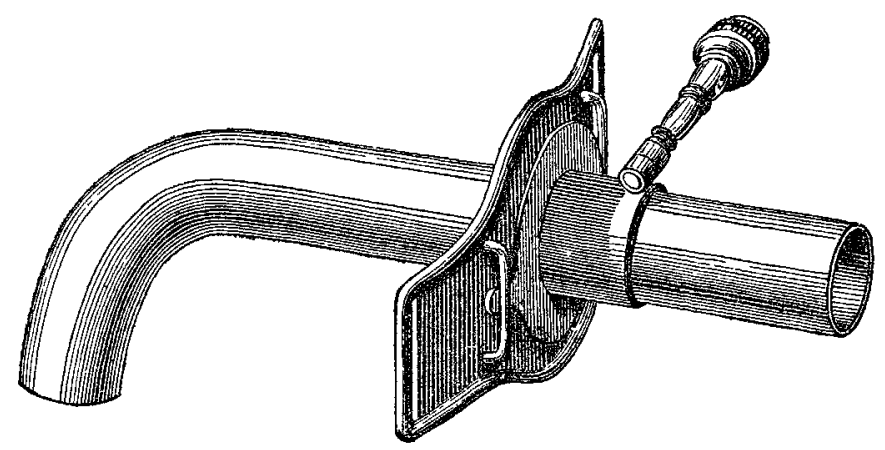

time of performing tracheotomy. Its inner cannula has to be made in rivetted segments (Fig. 10), otherwise it could

Fig. 10.

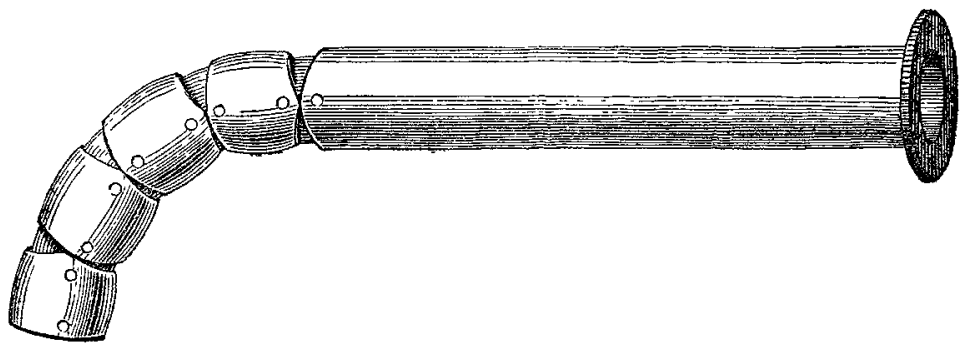

not be made to pass to the end of the outer right-angled cannula. This inner cannula projects, as in all forms of

FIg. 11.

FIG. 12.
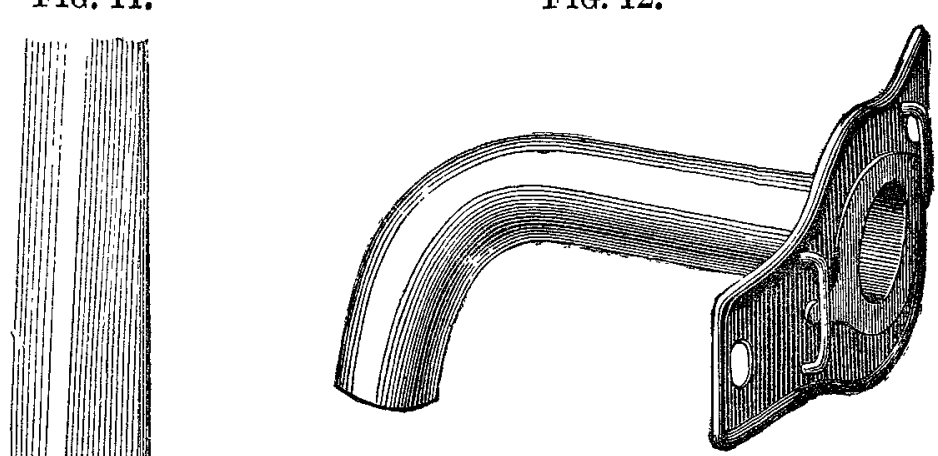

tubes, about one-tenth of an inch beyond the outer cannula. Properly made right-angled tubes have the orifice of the outer cannula at the tracheal end very slightly narrowed, so that, in the event of the end segment of the inner cannula breaking off, the broken piece cannot slip past and fall into the trachea; the rim of the upper end everted, so that the outer cannula cannot slip away from the shield and fall into the trachea; also-and this refers to all tubes - the projections on each side of the necklet of the outer cannula, which pass under the shield, made of sufficient length to prevent the cannula slipping from the shield into the trachea. Durham's tube, like others, excepting the bivalve, has a blunt-pointed trocar (Fig. 11), to enable it to be readily passed into the trachea. It is made, similarly to others, in four different sizes, suitable for adults, young people, children, and infants. The largest is 19 in English œesophageal gauge, or 31 in French gauge (31 millimetres in circumfrence): the second size, 17 in English, gauge, or 28 millimetres; the third, 15 in English, or 26 millimetres; the smallest, 12 in English, or 22 millimetres. A few days after tracheotomy has been performed a permanent Durham's tube (Fig 12), with or without inner cannula, can be made to messurement.

That very ad mirable cannula, Morrant Baker's rubber tube, 
nowadays, after the first few days of tracheotomy, takes the place of the silver instrument. It is made throughout its whole length with a mid layer of webbing, so that there is no fear of it suddenly breaking off short. As every tube after the third or fourth day of tracheotomy is taken out daily to be cleaned, so Morrant Baker's can daily be examined to see if it is sound. It should last for months, I may say a year, and should not cost more than four shillings. This is a tube which adds greatly to a patient's comfort by its lightness and flexibility. It is not to be recommended if there is excessive tracheal discharge, as it is not supplied with an inner cannula, or in cases where there is ossification of the cartilages.

Rather apart from the subject of this paper is the question of wearing a valve on the outside of the cannula, to enable the patient to speak without having to block the cannula with his finger. This can only be worn when the tracheal discharge has ceased. There are two kinds, Luer's pea valve, shown in Fig. 13, and Mr. T. Smith's indiarubber valve. Some patients like them, others do not.

FIG. 13.

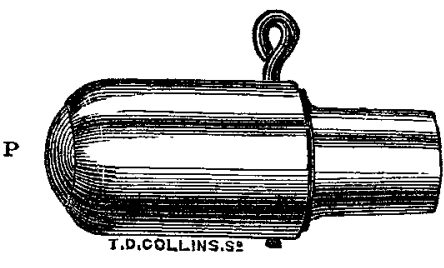

$P$, pea.

In visiting the following surgical instrument makers and dealers, I asked for the tracheotomy tube they recommended, and in each case, after being shown a tube, informed them for what purpose I had come. Every where I met with the utmost courtesy:-1. Frederick and Co., Lambeth-palace-road: Bivalve first, then Durham's and Parker's. 2. Millikin and Lawley, Strand: Bivalve, 3. Weiss and Son, Strand: Bivalve. 4. Maw and Son, Aldersgate-street: Bivalve, Parker's next. 5. Evans and Wormull, Stamford-street: Bivalve. 6. Hills and Co., Newcomen-street: Hilton's. 7. Down Brothers, St. Thomas's-street: Durham's. 8. Krohne and Sesemann, Whitechapel : Hilton's and Durham's. 9. Stephens, Smithfield: Bivalve or quarter-circle. 10. Arnold, West Smithfield : Bivalve. 11. Ferguson, West Smithfield: Bivalve. 12. Matthews, Carey-street: Matthews' Bivalve. 13. Baker, High Holborn: Bivalve. 14. Coxeter, Graftonstreet: Parker's, then bivalve. 15. Pratt and Co., Oxfordstreet: Bivalve. 16. Weiss and Son, Oxford-street: Quartercircle, and then bivalve. 17. Mayer and Meltzer, Great Portland-street: Durham's. 18. Krohne and Sesemann, Duke-street: Parker's. 19. Hawksley, Oxford-street: Bivalve (Matthews'), then quarter-cir $\cdot$ le. 20. Wright, New Bondstreet: Bivalve or quarter-circle. The following remarks were made on the bivalve-." Cheapest and most in request," "We sell 100 of the bivalve to one of Parker's." One firm, well known to me, recommended Durham's and no other, "but will sell you what you like." It will be seen that at these twenty shops the bivalve is recommended fifteen times, in three of the fifteen it being the first choice, and in seven the only one selected; Durham's and Parker's are divided equally between eight shops, two of the four in each case being first choice; Hilton's recommended at two places, and quarter-circle at four.

In so many tubes I noticed an elliptical piece cut out of the top of the tracheal portion. It is done with the idea of allowing air to pass to the vocal cords. This is totally unnecessary, for air can always pass by the outside of a tube sufficient for talking and respiration, even when the lumen of the larynx is restored, and the cannula is worn blocked by a cork. This elliptical opening often does harm, for the tracheal mucous membrane is apt to be sucked in and injured by its sharp sides. It is only useful when using laryngeal dilators, or for passing an instrument through when tracheotomy has been performed for foreign bodies in the larynx.

Some instrument makers recommend vulcanite tubes. If the walls are not made so thick that there is hardly any canal left they are very likely to break. I think vulcanite should be altogether discarded as a substance for tracheotomy tubes. Certainly that pretty, but fragile and highly inflammable stuff called celluloid should never be used. One of the instrument makers highly recommended me a celluloid cannula.
To my mind, of all these tubes in present use there is none to beat Durham's right-angled one. (Figs. 8, 9, 10, 11, 12.) It is the right shape-to wit, a straight piece for the wound, with a short piece at right angles to drop into the trachea without touching the back wall of the trachea. It is the easiest to insert. Then, again, no other tube can be lengthened or shortened according to the depth the trachea is found to be at the time of operating-a value that cannot be overstated. It has one great fault, but only one. The inner cannula from being made in rivetted segments is rough for half its interior, and so retains mucus more than it would were it smooth. But this roughness does not prevent its being easily pulled out for cleaning, if not left in for an inordinate length of time, as is quickly the case with Hilton's or Parker's inner cannulæ. These inner tubes, from being so much cut away, allow the tracheal discharge very soon to glue them tightly to their outer tubes. I think Durham's tube might with service be made slightly longer in the tracheal portion. I know of no plan for the improvement of the inner cannula. The double woven wire tube will not answer.

Parker's latest instrument (Fig. 7) is the next best, it seems to me, to Durham's. But it wants three improvements, two of which are very important ones: a facility for lengthening or shortening, a continuous inner tube, and an absence of the catch for holding the inner tube in place. This catch, so readily becoming clogged with discharge, will not often easily unfasten to allow the inner tube to be withdrawn, perhaps at an urgent moment.

The bivalve cannula (Figs. 3 and 4) I have an absolute horror of, with its cutting edges and quarter-circle shape. Though it appears to be the most common in use, I am confident it ought to be at once discarded for ever.

I think the same of the tube made in quarter-circle shape (Fig. 14). This and the bivalve are the tubes served out

FIG. 14.

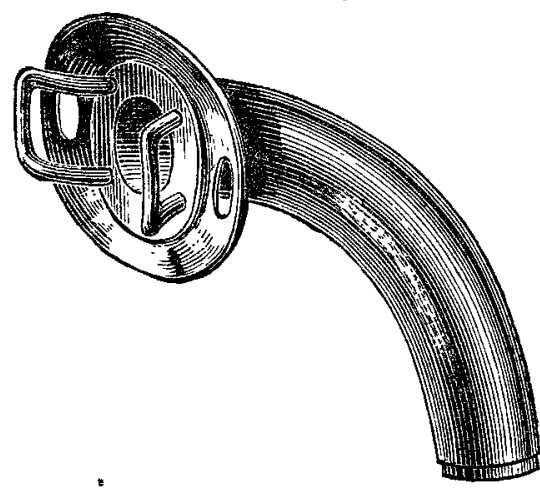

by Government to the army and navy and all institution under its management. It has, with the bivalve, the recommendation of being less expensive than other tubes, but the irritability it often sets up in the windpipe by tilting against the back wall of the trachea utterly destroys any other value it may have. This tilting is due to its quarter-circle, or curved-all-the-way, shape. Of course to Government, as well as to ordinary purchasers, expense must be a question, but if Durham's tubes were used for the first few days after tracheotomies, and then Morrant Baker's made the permanent instrument, the expense would come to no larger an item for then Durham's tubes would last much longer.

\section{PHTHISIS A DISEASE OF THE NIGHT.}

\section{Br R. J. SHEPHERD, M.D.}

Some fifty cases of phthisis die under my care annually, and have done so for the last dozen years. I do not pretend to have studied the question deeply, since my daily routine of duty absorbs pretty nearly all my energies, but naturally onough the question interests me deeply, and I should like to jot down a few of the thoughts that have passed through my mind concerning it. They may not even be new in themselves, but at least they will bear the impress of the mind through which they have passed, and they may serve to strike some sparks from brighter intellects. Phthisis is a subject of such vast importance that I feel no apology 